DOI: $10.7242 / 2658-705 X / 2019.1 .3$

УДК 323.2

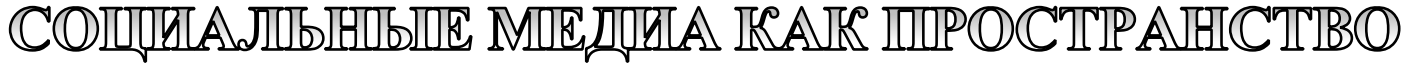

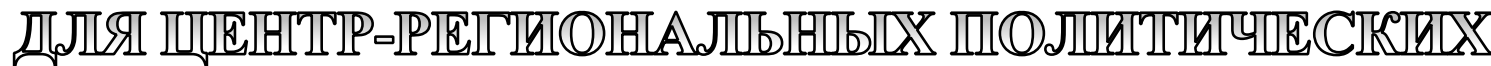

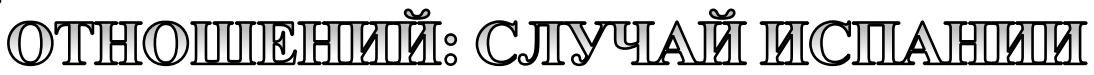

Е.Ю. Филиппова, Пермский федеральный исследовательский центр УрО РАН

Статья посвящена сравнительному анализу практик использования социальных медиа в контексте осмысления центр-региональных политических отношений главами исполнительной власти автономных сообществ Испании Галисии, Каталонии и Страны Басков. В качестве ключевого метода исследования использован сравнительный дискурс-анализ материалов, опубликованных в профилях Instagram рассматриваемых политических деятелей. Анализ позволил выявить три модели осмысления отношений между центром и регионами в испанском контексте: модель публичной лояльности центру и системе центр-региональных отношений (Галисия), модель отсутствия актуализации проблемы центр-региональных отношений, сопряженная с фрактической легитимацией сложившегося политического порядка (Страна Басков), и модель публичной конфронтации с центром (Каталония). Результаты исследования демонстрируют, что социальные медиа в цифровую эпоху становятся пространством для политики в контексте проблемы центр-региональных отношений - они не продуцируют ее новые формы, но создают новые возможности для акцентуации форм, существующих в офрлайн-режиме.

Ключевые слова: иентр-региональные отночения, этнорегиональные сообщества, Испания, Каталония, Галисия, Страна Басков, социальные медиа.

Изучение специфики центр-региональных отношений в федеративных и федерализирующихся государствах - исследовательский вектор, классический для политической науки и перманентно актуальный вследствие динамичного характера предмета исследования. Как подчеркивает, например, Р.Ф. Туровский, значимой характеристикой современного общемирового политического пространства выступает тенденция к тому, что «отношения между центром и регионами приобретают критическое значение для процессов государственного строительства» [4, с. 4-5].
Вместе с тем исследователи убедительно демонстрируют, что усложнение политического порядка в современном мире происходит по разным векторам, которые могут пересекаться друг с другом, образуя содержательно сложную констелляцию. Один из таких векторов - само по себе усложнение центр-региональных отношений, другой - цифровая эпоха, постепенно трансформирующая политический порядок посредством возрастающей роли социальных медиа как пространства для политики [6]. В поисках ответа на вопрос о том, при каких условиях происходит 
политизация социальных медиа, убедительной выглядит исследовательская логика А.В. Садиловой, которая отмечает, что «политический характер интернет-взаимодействие приобретает в процессе вхождения в сеть различных политических акторов, которые используют сетевое пространство в качестве места для общественных дискуссий и артикуляции собственного мнения» [3, с. 3]. Фиксируемая исследовательская логика определяет факт возможной включенности центр-региональных политических отношений в сетевое пространство, но не демонстрирует, какова роль социальных медиа для содержания таких отношений. Иными словами, неочевидными остаются границы использования инструментального потенциала интернет-пространства заинтересованными политическими акторами, включающимися в него посредством артикуляции собственных взглядов по поводу отношений по линии центр-регионы.

В статье в результате анализа корпуса эмпирического материала на примере испанского случая обосновывается предположение о том, что одна из возможных функций социальных медиа как пространства для центр-региональных политических отношений - усиление и публичная демонстрация тех форм таких отношений, которые сложились в офлайн политике. В этом смысле социальные медиа применительно к политико-теоретической проблеме отношений между центром и регионами становятся именно пространством для политики, а не пространством политики - они не продуцируют ее новые формы, но создают новые возможности для акцентуации прежних форм.

\section{Исследовательская логика: испанский контекст}

Принцип организации центр-региональных отношений в современной Испании в исследовательской литературе характеризуется как «государство автоно- мий» [2]. С.М. Хенкин определяет этот принцип как «гибридную форму, промежуточную между унитарным государством и федерацией», соглашаясь с вариантом его типологизации в качестве «регионалистского государства», встречающимся в исследовательской литературе [5]. Смысл «регионалистского государства» включает в себя высокую степень региональной самостоятельности, заданную институционализированными практиками, в сопряжении с высокой степенью этнорегиональной специфики автономных сообществ. В таких условиях проблема центр-региональных отношений приобретает особенную сложность, что закономерно проявляется в актуальных политических практиках.

Описываемое исследование представляет собой сравнительный анализ активности испанских региональных лидеров в сервисе Instagram (разновидность социальных медиа) по поводу осмысления центр-региональных отношений, сложившихся в государстве. Анализ позволил выявить модели осмысления политическими лидерами центр-региональных отношений в Испании в рамках публичного пространства социальной сети Instagram. В свою очередь, дополнительный анализ материалов СМИ и корпуса исследовательской литературы сделал возможным сопоставление онлайн и офлайн практик конструирования центр-региональных отношений в испанском случае.

Для анализа выбраны официальные (верифицированные) профили в Instagram четырех политических деятелей, среди которых:

- Иньиго Уркулью - действующий председатель правительства Страны Басков [9].

- Карлес Пучдемон - председатель правительства Каталонии, один из ключевых активистов борьбы региона за независимость [8].

- Альберто Фейхоо - действующий председатель правительства Галисии [7]. 
- Мариано Рахой - испанский премьерминистр, на период правления которого пришелся период оспаривания регионами сложившегося политического порядка [10].

Выбор случаев для рассмотрения обоснован тем, что Каталония, Галисия и Страна Басков традиционно оцениваются исследователями в качестве «локомотивов» испанского регионализма [1], а указанные политические деятели - лидерами его манифестации. Профиль экс-премьер-министра выбран, в свою очередь, в качестве дополнительного индикатора, характеризующего позицию Центра, по причине наибольшей активности такой манифестации в период его политической карьеры на посту главы исполнительной власти Испании.

Обозначенный подход к анализу социальных медиа как к пространству для политики предопределил блок теоретических ожиданий, сформулированных до предметного изучения выбранных профилей в Instagram. Так как Instagram - площадка экстернализации политической субъективности для широкой аудитории (фактически - для любого пользователя, который заинтересован в просмотре страницы), ожидалось, что транслируемые позиции по поводу системы центр-региональных отношений станут публичным осмыслением текущего или желаемого (планируемого) положения дел в этих отношениях.

Представляется, что демонстрировать текущее положение дел в социальных медиа рационально в том случае, если это положение либо сбалансировано в сторону нормальности, либо находится в дисбалансе (если речь идет, например, о конфликте региона с центром). Демонстрировать желаемое (планируемое) положение дел, напротив, рационально в случае его текущего аморфного состояния, когда статус центр-региональных отношений не до конца зафиксирован обеими сторонами. Другой очевидно возможный вариант отсутствие тематической демонстрации, обусловленное низкой степенью ее актуальности для конкретного региона.

Результаты мониторинга СМИ и тематических исследований делают проясненным, например, факт лояльного отношения правительства Галисии к правительству Испании. На протяжении 2000-х гг. Галисия - регион, стремящийся соглашаться с центром, быть с ним в едином дискурсивном поле и обеспечивать, тем самым, крепкие сбалансированные отношения. В этом смысле ожиданием от профиля в Instagram Альберто Фейхоо выступила демонстрация дружественности этих отношений как текущего положения вещей. Зависимость региона от унитарного центра (в первую очередь фискальная, т.к. более бедные регионы Испании вынуждены зависеть от налоговых перераспределений в свою пользу) при этом влечет за собой необходимость не просто «молчаливого» функционирования подобных отношений, а именно публичной демонстрации их статуса.

Другой пример - каталонское правительство, в 2000 г. находившееся в непримиримом конфликте с кабинетом Мариано Рахоя. Ожидание от профиля в Instagram Карлеса Пучдемона - активная демонстрация отсутствия лояльности к центру с целью популяризации идеи сецессионизма. Страна Басков ожидаемо может дать третий пример, когда регион выступает институционализированной особостью и не нуждается в публичной демонстрации своей позиции относительно центр-региональных отношений, т.к. не ощущает себя зависимым от них в важной степени.

Проведенный анализ обозначенных профилей в Instagram подтвердил сформулированные теоретические ожидания. Далее в тексте представлены результаты анализа каждой исследуемой страницы, позволяющие составить представление о публичной интерпретации характера центр-региональных отношений в современной Испании каждым из рассматриваемых политических лидеров. 


\section{Результаты анализа профилей B Instagram}

На своей странице в Instagram Mapuaно Рахой (премьер-министр Испании) подчеркивает, что сложившаяся система организации центр-региональных отношений в Испании институционализирована, закреплена в Конституции, и ни один регион не имеет права ее менять. Например, пост в Instagram от 2 октября 2017 г. фиксирует: «Сегодня не было референдума о самоопределении, а организована борьба против законности; Верховенство закона сохраняет свою силу. Лидеры Каталонии хотели отменить Конституцию и национальный суверенитет. Они несут ответственность за ситуацию, к которой нас привели» [10]. Следует пояснить, что речь идет о ситуации с референдумом в Каталонии, проведенном без согласия официального Центра осенью 2017 г.

Для М. Рахоя, очевидно, важно соблюдение принципа легальности закон превыше всего, в том числе в отношении выстраивания системы взаимоотношений между центром и регионами. Например, в посте от 27 октября 2017 г. он просит «спокойствия для всех испанцев. Верховенство закона восстановит законность в \#Каталонии» [10].

Артикулируемый сюжет, вновь связанный с Каталонией, определяет первичность закона по отношению к неформальным практикам, внедряемым регионами в абсолютном конфликте с позицией Центра. «Испания - это государство, которое имеет надлежащче механизмы для защчиты законов, которые мы дали, чтобы жить вместе в условиях свободы. Я гарантирую свою решимость обеспечить его соблюдение, на карту поставлена основа намей демократии» [10] - премьер-министр вновь обращается к теме законности на своей странице 21 сентября 2017 г.

Основа сложившихся центр-региональных отношений, таким образом «искренний диалог» в рамках закона.
В этой связи интересен пост М. Рахоя от 20 сентября 2015 г.: «Испания немыслима без \#Каталонии и \#Каталония немыслима без \#Испании. Наши сердиа бьются \#вместе. \#ViscaEspanya \# VivaCataluña», который можно интерпретировать как попытку инициировать подобный «искренний диалог» [10].

Первичность закона, что важно, подчеркивается не только в отношении Каталонии, но и других автономных сообществ Испании, которые каким-то образом вступают в противоречие с этим принципом. Любая попытка перестроить сложившуюся систему центр-региональных отношений в Испании в логике М. Рахоя - борьба против законности. Так, запись от 3 мая 2018 г. посвящена уже не Каталонии, а ситуации в Стране Басков - «ЭТА (террористическая организация, Страна Басков) была побеждена силой верховенства закона и испанской демократии» [10].

Обращает на себя внимание тот факт, что испанский премьер-министр на своей странице в социальной сети уделяет большое внимание попытке интегрировать мозаичные автономные сообщества в дискурс гражданской нации. Испанцы единая нация, основанная на принципе согражданства, где галисиец, каталонец или басконец - жители одной страны, подчеркивает М. Рахой. Не вызывает, поэтому, удивления тот факт, что в профиле премьера отсутствуют публикации про региональные различия: особость автономных сообществ признается, но внимание на ней публично не акцентуируется.

Кроме того, в онлайн-риторике М. Рахоя важное место занимает «значимый другой» - Европейский союз, выступающий стратегически важным актором, официально и публично поддерживающим испанское правительство по вопросам сохранения целостности государства. Неслучайно, поэтому, премьер определяет Европейский союз как ценность, 
к максимальной включенности в которую необходимо стремиться. Запись от 9 мая 2018 г. фиксирует: «Mbl отмечаем мир и единство вокруг проекта, который позволил нам достичь самых высоких уровней благосостояния в нашей истории. \#Испания будет и впредь убежденно содействовать развитию Европейского союза» [10].

Иньиго Уркулью, лидер исполнительной власти Страны Басков, в своем Instagram расставляет акцент на политической самостоятельности региона. В его профиле часто встречаются истории о двусторонних встречах с политическими лидерами за пределами Испании. Например, 20 января 2016 г. был опубликован пост о том, что «\#Франциско Морено, губернатор Керетаро (Мексика), встретился со \#Страной Басков, чтобы далее укрепить наши отношения, традиционно связанные с этим штатом Мексики» [9]. Значимый формат публикации в Instagram для И. Уркулью - отчет о встречах с европейскими представителями, с главами других стран. Так, 28 февраля 2016 г. он пишет «Вместе с генеральным секретарем иностранных дел Марианом Элорзой мы приняли франиузского посла Ив Сен-Жёра» [9].

Более развитая Страна Басков - самый сильный приоритет для главы региона, что подчеркивается в его странице в рассматриваемой социальной сети. «На конференuии «Страна Басков 2020», организованной Университетом Деусто, выступил с речью: “Следующее поколение - более развитая страна, моя самая большая приверженность и энтузиазм», - пишет Глава Басконии 28 февраля 2016 г. [9].

Также в профиле в Instagram И. Уркулью обнаруживается акцент на политическую субъектность региона (например, есть посты про штаб-квартиры баскского правительства в Париже, Брюсселе). Так, пост от 6 июля 2016 г. рассказывает пользователям: «Mbl подошли $\kappa$ штаб- квартире правительства Странь Басков в Париже, на улице Марсо, захват которой нацистами в 1940 году был ужасным событием. В 1951 году штаб-квартира перешла в руки испанского правительства во времена режима Франко. Воспользовавшись нашим присутствием, мь оставили записку в этом историческом здании для баскского правительства, напоминая, кому оно принадлежало» [9].

В общую логику аккаунта И. Уркулью укладывается и тот факт, что в его профиле не опубликовано ни одного поста про Испанию, про центральное правительство и про те тематические области, которые были бы связаны не только со Страной Басков, но и собственно с кастильской частью политического сообщества.

Критический вариант осмысления центр-региональных отношений в случае Испании представляет собой аккаунт в Instagram Карлеса Пучдемона - лидера борьбы за независимость Каталонии. «Перестроение центр-региональных отношений - наше (каталонское) право», пишет К. Пучдемон. Это показательно отражено, например, в посте от 2 марта 2018 г.: «Я полностью уверен, что мы победим в своей борьбе за независимость. Мы продолжаем нашу правовую и политическую борьбу до конияа, потому что у нас есть на это наше право» [8]. Несвобода и страх - то, что по мнению каталонского лидера характеризует текущие отношения между центром и регионами. "Испанское правительство не ведет переговоры: наказывает и унижает; Месть вместо справедливости», - отмечает К. Пучдемон 20 сентября 2018 г., подчеркивая, что испанское государство хочет, чтобы каталонское правительство «стояло перед ним на коленях» [8].

Важное место в онлайн-риторике каталонского лидера занимает апеллирование к ценностям демократии. «Mbl можем добавить, что ни со временем, ни перед личом всех антидемократических 
мерзостей, которые ведут к безнаказанности, мы не перестанем выступать за свободу прессы, за каталонские инстиmутьл и за демократию», - пишет он 21 мая 2018 г. [8]. Чуть ранее, 2 мая 2018 г., политик также высказывается на тему ценностей демократии: «Только слабые навязывают политических соперников. Вице-президент @junqueras и советник@joaquimforn6 месяцев назад стали заложниками демократической деградации в Испании, но их пример и их ценности являются основой Республики свободы. Мы уйдем!» [8].

Испанское государство для К. Пучдемона - репрессивная машина, о чем он пишет в своем посте от 3 апреля 2018 г.: «Не позволяйте страху победить вас. Режим террора, который они пытаются навязать в Каталонии, является оправданием для репрессий. Не позволяйте себе закрываться в тюрьмах самоцензуpbl. \#Catalana Republic будет настолько свободна, насколько вы захотите» [8].

Как и в случае Страны Басков, в профиле лидера Каталонии обнаруживается акцент на политическую субъектность региона (например, есть посты про штабквартиры каталонского правительства в Брюсселе). Отношение к Европейскому союзу при этом демонстрируется в сдержанно-скептическом ракурсе, и 26 октября 2018 г. К. Пучдемон пишет: «Де-факто терпимость ЕС к насилию в прошлом году, а такље существование политических заключенных и изгнанных лидеров, посылает тревожный сигнал для будущего Европь»» [8].

Другой вариант осмысления центр-региональных отношений в контексте современной Испании демонстрирует галисийский лидер Альберто Фейхоо. Множество постов в его профиле в Instagram, в отличие от И. Уркулью из Страны Басков, посвящено сюжетам об Испании, о национальном единстве, о национальных праздниках. Например, запись от 14 октября 2018 г. посвящена военному параду, который «отмечается по случаю Дня национального праздника Испании в Мадриде» [7].

Обращает на себя внимание наличие большого количества совместных фотографий А. Фейхоо с М. Рахоем (испанским премьер-министром), демонстрирующих очевидную публичную поддержку центра (публичная поддержка центра выражается, например, в том, что на фотографиях А. Фейхоо обнимает М. Рахоя). 17 декабря 2015 г. А. Фейхоо публикует пост в поддержку премьера: "Наше самое абсолютное осуждение и неприятие агрессии, от которой пострадал@marianorajoy. В демократии насилие не подходит. \#ЯвместесРахоем» [7]. При этом кризисные ситуации - не единственный информационный повод для публикации совместных фотографий. В записи от 27 марта 2014 г., например, лидер Галисии поздравляет испанского премьера с праздником: «27 марта! Настоящим я отдаю должное дню рождения нашего президента Мариано Рахоя» [7].

Помимо политической фигуры премьер-министра в профиле А. Фейхоо часто встречаются фотографии с Королем Испании - гарантом Конституции и символической фигурой, свидетельствующей о единстве испанской гражданской нации. «Акт Юры де Бандейры и сдача королевских контор в Военно-морском училище в Марине под председательством Его Величества эль-Рей Дона Фелипе VI», - пишет галисийский лидер 20 июля 2015 г., сопровождая пост совместной фотографией с Филиппом VI [7].

Демонстрируемая в профиле в Instagram Главы Галисии политическая лояльность центру и значимость общеиспанского фактора в пространстве региона сбалансирована, вместе с тем, историями про Галисию и ее этнорегиональные маркеры. «Я хочу, чтобы Фестиваль вина Альбариньо был объявлен международным событием и превратил его 
в первый галисийский праздник вина», такую запись А. Фейхоо публикует 8 августа 2018 г., делая акцент на этнорегиональной особости [7].

Проведенный анализ позволил выявить модели осмысления политическими лидерами центр-региональных отношений в Испании в рамках публичного пространства социальной сети Instagram, которые можно условно обозначить следующим образом:

1. Галисия - «Мы с вами и будем с вами». Модель публичной лояльности центру и системе центр-региональных отношений, активно демонстрируемая в аккаунте главы региона.

2. Страна Басков - «Мы самостоятельны, но вписаны в ваше пространство и соглашаемся с этим». Модель отсутствия актуализации проблемы центр-региональных отношений в профиле в Instagram главы региона, сопряженная с фактической легитимацией сложившегося политического порядка.

3. Каталония - «Мы особые и свободные, и мы не хотим быть с вами».
Модель публичной конфронтации с центром и системой центр-региональных отношений, активно демонстрируемая в аккаунте главы региона.

Таким образом, сформулированные теоретические ожидания оказались подтвержденными: социальные медиа выступают «содержательным зеркалом» центр-региональных отношений, сложившихся в испанской традиционной (офлайн) политике. Всё это, по-видимому, означает, что одна из возможных функций социальных сетей в цифровую эпоху применительно к проблеме центррегиональных отношений - усиление и публичная демонстрация тех форм таких отношений, которые сложились в офлайн политике. В этом смысле социальные медиа применительно к политикотеоретической проблеме отношений между центром и регионами становятся именно пространством для политики, а не пространством политики - они не продуцируют ее новые формы, но создают новые возможности для акцентуации прежних форм.

\section{Библиографический список}

1. Богатырева O.Н. Европейские модели регионализма: учеб. пособие / М-во образования и науки РФ, Урал. федер. ун-т. - Екатеринбург: Изд-во Урал. ун-та, 2018. - 171 с.

2. Волкова Г.И. Испания: государство автономий и проблема территориальной целостности. - М.: МАКС Пресс, 2011. - 328 с.

3. Садилова A.B. Технологии взаимодействия власти и общества в интернет-практиках в 2000-е годы: автореф. дис ... канд. наук. - М.: МГУ им. М.В. Ломоносова, 2017. - 27 с.

4. Туровский Р.Ф. Баланс политических отношений между центром и регионами в процессах государственного строительства: автореф. дис... д-ра полит. наук. - М.: МГУ им. М.В. Ломоносова, 2007. - 54 с.

5. Хенкин С.М. Государство автономий: проблемы и перспективы // Пространство и время в мировой политике и международных отношениях: Материалы 4-го Конвента РАМИ. - М.: МГИМО Университет, 2007. - С. 29-35.

6. Castellano Parra Orge, Larrondo Ureta Ainara, Peña Fernández Simón. Online communication spaces and their impact on Basque politics: strategies for a dialogue 2.0 // Actas del III simposio internacional sobre gestión de la comunicación la innovación de la innovación: del medio al contenido predictive - 2018. - P. 457-470.

7. Instagram. Alberto Núñez Feijóo. Xunta de Galicia. [Электронный pecypc] - URL: https://www.instagram.com/feijoogalicia/ (дата обращения: 01.02.2019).

8. Instagram. Carles Puigdemont. 130è President de Catalunya. [Электронный pecypc] - URL: https://www.instagram.com/carlespuigdemont/?hl=ru (дата обращения: 01.02.2019).

9. Instagram. Iñigo Urkullu lehendakariari buruzko kontu ofiziala Instagramen. Cuenta oficial en Instagram de información sobre el lehendakari Iñigo Urkullu. [Электронный pecypc] - URL: https://www.instagram.com/iurkullu/ (дата обращения: 01.02.2019).

10. Instagram. Mariano Rajoy Brey. Afiliado al Partido Popular. Creo en \#España, un gran país, una historia de éxito. [Электронный ресурс] - URL: https://www.instagram.com/marianorajoy/?hl=ru (дата обращения: 01.02.2019). 


\title{
SOCIAL MEDIA AS SPACE FOR CENTER-REGIONAL POLITICAL RELATIONS: THE CASE OF SPAIN
}

\author{
E.Yu. Filippova \\ Perm Federal Research Centre UB RAS
}

The article is devoted to the comparative analysis of the practices of using social media in the context of center-regional political relations as understood by the chief executives of the autonomous communities in Spain - Galicia, Catalonia and the Basque Country. A comparative discourse analysis of materials published on Instagram profiles of the politicians was used as a key research method. The analysis allowed to reveal three models for understanding the relations between the center and the regions in the Spanish context: the model of public loyalty to the center and to the center-regional relations system (Galicia), the model of the absence of actualization of the centerregional relations problem combined with the actual legitimization of the existing political order (Basque Country) and the model of public confrontation with the center (Catalonia). The results of the study demonstrate that social media in the digital era are becoming a political space in the context of the center-regional relationship problem - they do not produce its new forms, but they create new opportunities for accentuating the forms existing in the offline mode.

Keywords: center-regional relations, ethno-regional communities, Spain, Catalonia, Galicia, the Basque Country, social media, political space.

\section{Сведения об авторе}

Филиппова Евгения Юрьевна, специалист научно-организационного отдела, Пермский федеральный исследовательский центр УрО РАН (ПФИЦ УрО РАН), 614900, г. Пермь, ул. Ленина, 13А; e-mail: eugenia_philippova@mail.ru 